\title{
Covid-19 en el Perú: respuestas estatales y sociales*
}

\author{
Covid-19 in Peru: state and social responses
}

\author{
Jorge Lossio ${ }^{i}$ \\ i Profesor Principal, Facultad de Letras y \\ Ciencias Humanas (Historia)/Pontificia \\ Universidad Católica del Perú. \\ Lima - Perú \\ orcid.org/0000-0001-9883-2048 \\ jorgelossio@gmail.com
}

Recebido em 30 ago. 2020. Aprovado em 2 set. 2020.
LOSSIO, Jorge. Covid-19 en el Perú: respuestas estatales y sociales. História, Ciências, Saúde - Manguinhos, Rio de Janeiro, v.28, n.2, abr.-jun. 2021, p.581-585.

\section{Resumen}

A pesar de los esfuerzos del Estado por contener la llegada y propagación de la covid-19, que comprendió una cuarentena estricta a nivel nacional por más de cien días, el Perú fue uno de los países en el mundo con más casos y número de muertes por la pandemia. La pandemia hizo visible la precariedad del sistema de salud, del empleo, de las condiciones de vivienda y transporte. Demostró además que mientras no se resuelvan problemas de fondo en el sistema social y económico del país, es poco lo que se puede hacer desde el sector salud para confrontar una crisis sanitaria. Este artículo analiza las respuestas estatales y sociales a la pandemia entre febrero y agosto del 2020.

Palabras clave: historia; covid-19; Perú; pobreza; cuarentena.

\begin{abstract}
Despite efforts by the Peruvian state to contain the outbreak and spread of covid-19, including a strict nationwide quarantine for more than one hundred days, Peru had one of the highest numbers of cases and deaths in the world due to the pandemic. The pandemic highlighted the precariousness of the health care system, work, living conditions and transport. The pandemic also demonstrated that until underlying problems in the country's social and economic system are solved (such as inequality and poverty), the health sector can do little to combat a health care crisis. This article analyzes state and societal responses to the pandemic between February and August 2020.
\end{abstract}

Keywords: history; covid-19; Peru; poverty; quarantine. 


\section{La reacción inicial del Estado peruano}

En diciembre de 2019 se anunció en China la aparición de una neumonía atípica que estaba ocasionando enfermedad y muerte en los alrededores del mercado de mariscos de Wuhan, en la zona central de ese país. En enero del 2020 se confirmó que se trataba de un coronavirus bastante contagioso y letal, frente a lo cual el gobierno chino ordenó una cuarentena estricta en Hubei (región de 60 millones de habitantes, incluyendo su capital Wuhan). Hacia mediados de enero de 2020 el virus ya se estaba propagando por el resto de Asia, Norteamérica y Europa. El primero de febrero de 2020, la ministra de Salud María Elizabeth Jacqueline Hinostroza Pereyra, médica cirujana graduada de la universidad de San Marcos, presentó el plan nacional de preparación y respuesta frente al riesgo de introducción del coronavirus 2019-nCoV.

La lectura de este plan nos muestra que la idea del Estado peruano era, en primera instancia, evitar que el virus ingresara al país. Para ello se puso especial atención a los pasajeros que llegaban desde Asia. En segunda instancia, se buscó mejorar nuestra capacidad para diagnosticar (se dispuso la compra de pruebas moleculares, por ejemplo). El Centro Nacional de Epidemiología, Prevención y Control de Enfermedades identificó como riesgos y limitaciones en el Perú el alto número de turistas chinos que llegaban al país (segundo lugar de origen de los turistas que cada año llegaban al Perú), la falta de infraestructura hospitalaria, el hacinamiento y la limitada oferta de unidades de cuidado intensivo en el país. Hasta fines de febrero las respuestas estuvieron dirigidas a evitar que el virus llegase al país, aunque no se cerró inicialmente el Aeropuerto Internacional Jorge Chávez.

No fue sino hasta el 6 de marzo de 2020 que el presidente Martín Vizcarra confirmó el primer caso de covid-19 en el país. El paciente cero fue un hombre de 25 años, piloto de Latam Airlines, que estuvo de vacaciones por España, Francia y República Checa. Al día siguiente, el 7 de marzo, se confirmaron seis casos. Una vez que se detectó el primer caso en Perú y empezó la propagación autóctona, las respuestas estatales se orientaron a evitar una propagación exponencial, informar a la población sobre el coronavirus y mejorar la infraestructura hospitalaria. El 8 de marzo se confirmaron siete casos. El 9 de marzo el Ministerio de Salud estableció la línea 113 (línea telefónica) para que la población pudiera informarse y avisar de posibles casos. De igual manera se emprendió una agresiva campaña de información sobre cómo evitar el contagio de la covid-19. Sin embargo, una limitación fue la incapacidad de un sector de la población de comprender o aceptar conceptos como el del portador asintomático, virus o contagio.

El 10 de marzo, con 11 casos registrados oficialmente en el país, el presidente Martín Vizcarra anunció cuarentena domiciliaria de 14 días para todos los viajeros provenientes de España, Francia, Italia y China. Al día siguiente, el 11 de marzo, Vizcarra anunció el cierre de las escuelas públicas y privadas. Inicialmente el cierre de escuelas se anunció hasta el lunes 30 de marzo, pero luego se extendió a todo el año escolar. El 12 de marzo, con 22 casos, el gobierno decretó emergencia sanitaria a nivel nacional durante un periodo de noventa días. La ministra de Salud, Elizabeth Hinostroza, enfatizó la importancia del aislamiento social, y el gobierno prohibió los espectáculos públicos que congregaran a más de trescientas personas. Ese mismo día, el 12 de marzo de 2020, el gobierno creó la 
Comisión Multisectorial de Alto Nivel para que conduzca las labores de coordinación y articulación orientadas a la prevención, protección y control de la covid-19. El 13 de marzo con 38 casos el gobierno decretó la suspensión de los vuelos procedentes de Europa y Asia desde el 16 de marzo. Al día siguiente el Ministerio de Cultura suspendió la atención en museos, bibliotecas y teatros.

Junto con prohibir la entrada de visitantes de países afectados por el mal y promover el aislamiento social, el gobierno buscó mejorar la infraestructura hospitalaria y la capacidad del sistema para luchar contra el coronavirus. El Ministerio de Salud dispuso cien millones de soles para la lucha contra la covid-19 (contratación de personal y compra de ambulancias, insumos y equipos biomédicos), y el presidente anunció que la Villa Panamericana, construida para los deportistas que llegaron para disputar los juegos panamericanos, sería destinada para los pacientes con covid-19. Por su parte, el alcalde de Lima, Jorge Muñoz, anunció que la Plaza de Acho se usaría para albergar indigentes. Este tipo de medidas improvisadas y de emergencia reflejaba la falta de inversión en salud a lo largo de décadas. Hay que recordar que en la década de los 1990s el Perú adoptó una política neoliberal y discursos que enfatizaban la responsabilidad individual en materia de salud (Cueto, 1997). En Perú en 2020 se contaba con 773 camas en UCI en total, número muy bajo incluso para el nivel de América Latina. También se hizo evidente la falta de respiradores para los casos críticos de covid-19. El 3 de abril el Comando de Operaciones Covid-19 señaló que había disposición de quinientos ventiladores mecánicos, lo cual por supuesto resultó insuficiente.

A pesar de estas medidas, los casos seguían incrementándose exponencialmente. Entonces el gobierno decretó una cuarentena estricta a nivel nacional.

\section{La cuarentena}

El domingo 15 de marzo de 2020, cuando habían 71 casos oficialmente registrados en el Perú, se inició una cuarentena que se pensó inicialmente duraría dos semanas, pero que duró hasta el 26 de junio. Los más de cien días de cuarentena drástica en el Perú, durante la cual solo se podía salir para compras esenciales (farmacias, mercados y bancos), fue una experiencia inédita en la historia y de consecuencias culturales y económicas aún difíciles de medir. Desde el punto de vista de las autoridades de la salud se esperaba que la cuarentena retrasaría los contagios y el número de muertes y así se evitaría el colapso del sistema de salud. La de la covid-19 fue la cuarentena más larga y extendida de la historia peruana.

El gobierno fue consciente que la cuarentena iba a tener un impacto económico de magnitud y dio una serie de incentivos económicos, más aún considerando que el Perú tenía una economía principalmente informal. Para paliar el impacto económico, el 16 de marzo, el gobierno anunció el otorgamiento de un bono de 380 soles para las familias vulnerables. Cuando se prolongó la cuarentena, el 26 de marzo, hay que recordar que se pensó inicialmente en 15 días. El gobierno autorizó el retiro de la compensación por tiempo de servicio por un máximo de 2.400 soles y decidió suspender los aportes de los trabajadores a las Asociaciones de Fondos de Pensiones (AFP). Es decir, se dieron una serie de incentivos económicos para evitar el colapso de la economía familiar, principalmente 
entre los sectores menos favorecidos. Así mismo, para evitar una depresión, el Ministerio de Economía y Finanzas señaló que inyectaría liquidez en la economía. A inicios de abril, el gobierno lanzó el programa Reactiva Perú inicialmente con un fondo de 30.000 millones de soles para financiar a empresas con interés casi nulo.

A cinco días de iniciada la cuarentena, la ministra de Salud, Elizabeth Hinostroza, fue removida del cargo, y Víctor Zamora Mesía juramentó como tal. La cuarentena tuvo varias limitaciones. Una fue la desobediencia en un sector de la población. Para el 7 de abril se había detenido a 52 mil personas por no respetar el aislamiento social. La informalidad y la precariedad laboral llevó en parte a desobedecer a la cuarentena. En el caso peruano la desobediencia a la cuarentena se debió más a realidades económicas que hacían imposible a un sector de la población cumplir con la misma. Lo económico no era lo único ciertamente. También contribuyeron una tradicional falta de respeto a la autoridad e incredulidad en algunos sectores de la población sobre la realidad del coronavirus y el contagio (Lossio, 2011). De igual manera, el comercio electrónico era aún limitado a algunos distritos de la capital, el hacinamiento de algunos distritos hacía imposible aislar a los enfermos y una realidad económica precaria e informal determinaba que muchos peruanos tuvieran que desoír el llamado a permanecer en sus casas.

La cuarentena general acabó el 26 de junio de 2020.

\section{Consideraciones finales}

La cuarentena no funcionó en Perú. Si al empezar la cuarentena teníamos 71 casos confirmados y ninguna muerte, al terminar la misma teníamos 268.602 casos confirmados y 8.761 fallecidos. Es decir, durante la cuarentena los casos y muertes crecieron de forma exponencial. Al terminar la cuarentena estábamos entre los cinco países con más casos confirmados de coronavirus. ¿Por qué fracasó la cuarentena en Perú? En primer lugar, factores socio-económicos. La necesidad económica de un sector alto de la población que tenía que salir a vender a la calle, a pesar de los riesgos. Hay que recordar que aproximadamente el 70\% de la población en Perú vive de la venta diaria en una economía informal. En segundo lugar, muchas familias en el caso de Lima viven en zonas alejadas de los centros de la ciudad donde no llega el delivery o se vive del día a día, por lo cual había que salir de forma casi cotidiana a hacer compras. En tercer lugar, el hacinamiento en los hogares. En viviendas hacinadas es imposible mantener la distancia social o aislar a los enfermos.

De igual manera, el fracaso de las respuestas estatales se debió a la precariedad en el sistema de salud pública: no había suficientes laboratorios que hicieran pruebas moleculares, no había suficientes camas en UCI, suficientes respiradores etc. La diversidad cultural y la poca cultura científica hizo que mucha gente no creyera o no entendiera conceptos como portador asintomático, contagio, virus. Esto último indica la importancia de la participación de psicólogos, científicos sociales e historiadores en el diseño e implementación de los mensajes de salud. El fracaso de la cuarentena hizo que la atención y las esperanzas del gobierno y la población se centraran en la llegada pronta de una vacuna, aunque para el momento de escribir este artículo, agosto de 2020, aún se hallaban en fase de prueba. 
NOTA

*El siguiente texto es una versión más completa, actualizada y sometida a revisión de pares de un post que apareció en el blog de História, Ciências, Saúde - Manguinhos.

\section{REFERENCIAS}

CUETO, Marcos. El regreso de las epidemias: salud y sociedad en el Perú del siglo XX. Lima: IEP, 1997.

LOSSIO, Jorge. Estado, prensa y sociedad frente a la influenza AH1N1. Lima: Tarea, 2011.

\section{$\rightarrow \rightarrow \rightarrow<<$}

